\title{
Oportunidades no mercado de trabalho: análise das vagas de emprego disponíveis para pessoas com deficiência
}

\section{Opportunities in the labor market: analysis of job vacancies available for people with disabilities}

Fabiana Caetano Martins Silva e Dutra ${ }^{\mathrm{a}, \mathrm{b}, \mathrm{c}}$ (D), Isadora Teixeira Mendes Paz ${ }^{\mathrm{b}}$ (D), Alessandra Cavalcanti $^{\mathrm{a}}$ (D), Alberto Luiz Aramaki ${ }^{\mathrm{b}, \mathrm{c}}$ (D), Edinara Kososki ${ }^{\mathrm{b}, \mathrm{c}}$ (D)

${ }^{a}$ Universidade Federal do Triângulo Mineiro - UFTM, Uberaba, MG, Brasil.

bNúcleo de Estudos e Pesquisas em Trabalho, Participação Social e Saúde - NETRAS, Universidade Federal do

Triângulo Mineiro - UFTM, Uberaba, MG, Brasil.

'Programa de Pós-Graduação em Atenção à Saúde - PPGAS, Universidade Federal do Triângulo Mineiro - UFTM,

Uberaba, MG, Brasil.

Como citar: Dutra, F. C. M. S., Paz, I. T. M., Cavalcanti, A., Aramaki, A. L., \& Kososki, E. (2020).

Oportunidades no mercado de trabalho: análise das vagas de emprego disponíveis para pessoas com deficiência. Cadernos Brasileiros de Terapia Ocupacional. 28(1), 147-163. https://doi.org/10.4322/25268910.ctoAO1724

\begin{abstract}
$\underline{\text { Resumo }}$
Introduçáo: A contratação de pessoas com deficiência pelo mercado formal de trabalho é obrigatória no Brasil por meio de cotas legais estabelecidas a empresas públicas e privadas. No entanto, vários fatores dificultam a inserção profissional dessas pessoas. Objetivo: Analisar e descrever as características das vagas de emprego oferecidas para pessoas com deficiência durante o período de um ano. Método: Estudo descritivo que analisou as características das vagas ofertadas em agências de emprego e mídias de comunicação em massa, no período de 2014 a 2015, para pessoas com deficiência na Microrregiāo de Uberaba, na Macrorregião Triângulo Sul/MG, Brasil. Resultados: Foram identificadas 87 vagas. A maioria não disponibilizava informaçôes importantes, como sexo, faixa etária, escolaridade ou requisitos específicos, como experiência prévia. A maioria também não informava sobre a empresa, o ramo da economia e o cargo ou função a ser desempenhado. Conclusão: A maioria dos anúncios de emprego tinham restriçôes nos dados disponíveis, dificultando o acesso à informação sobre as vagas. Houve predomínio de vagas caracterizadas como ocupaçôes com menor exigência de escolaridade e qualificação técnico-profissional e com baixa remuneração.
\end{abstract}

Palavras-chave: Inclusão, Emprego, Pessoas com Deficiência, Mercado de Trabalho, Terapia Ocupacional. 


\begin{abstract}
$\underline{\text { Abstract }}$
Introduction: Hiring people with disabilities in the labor market is mandatory in Brazil through legal quotas established for public and private companies. However, several factors hamper the professional insertion of this people. Objective: To analyze and describe the characteristics of the job vacancies offered to people with disabilities, during the period of one year. Method: A descriptive study that analyzed the characteristics of vacancies offered in employment agencies and mass communication media, from the years 2014 to 2015, for people with disabilities in the Uberaba Microregion, located in the Triângulo Sul Macroregion/ MG, Brazil. Results: Only 87 openings were identified. The majority did not provide important information such as gender, age, education or requirements such as prior experience. The majority also did not report about the company, the branch of the economy and the job or function. Conclusion: Most work ads had restricted information about the job requirements. There was a predominance of vacancies characterized as occupations with poorer requirements on schooling, technical and professional qualification and with low remuneration.
\end{abstract}

Keywords: Inclusion, Employment, Disabled Persons, Job Market, Occupational Therapy.

\title{
1 Introduçáo
}

Historicamente, pessoas com deficiência foram privadas de se envolverem em diferentes atividades cotidianas, como estudar e trabalhar e, consequentemente, tiveram restrição de participação social no contexto familiar e da comunidade em que estavam inseridas. Somente a partir da segunda metade do século passado é que surgiram discussóes a respeito dos direitos das pessoas com deficiência e sua inclusão na sociedade (Carvalho, 2009; Sempertegui, 2015). De acordo com a Pesquisa Mundial de Saúde, cerca de 785 milhóes de pessoas (15,6\%) com 15 anos ou mais vivem com algum tipo de deficiência (Organização Mundial da Saúde, 2011). O Brasil tem cerca de 45,6 milhóes de pessoas com algum tipo de deficiência - física, intelectual ou sensorial e representam 23,6\% da força de trabalho (Instituto Brasileiro de Geografia e Estatística, 2015). No entanto, segundo o Instituto Brasileiro de Geografia e Estatística (2015), 54\% de pessoas com deficiência estavam desocupadas ou não eram economicamente ativas no último censo.

Para a compreensão e abordagem da funcionalidade humana, atualmente, o principal orientador tem sido o modelo da Classificação Internacional de Funcionalidade, Incapacidade e Saúde (CIF) da Organização Mundial de Saúde (OMS) (Organização Mundial da Saúde, 2003). De acordo com a CIF, a incapacidade resulta da "[...] interação dinâmica entre os estados de saúde e os fatores contextuais" (Organização Mundial da Saúde, 2003, p. 19). Nesta perspectiva, açóes de inclusão devem abranger programas e políticas desenvolvidos em diferentes contextos para fornecer oportunidades para o envolvimento de pessoas com deficiência em ocupaçóes desejadas ou necessárias. Assim, em uma esfera internacional, um incremento destas 
ações passou a reconhecer direitos das pessoas com deficiência e garantir iguais oportunidades, como observado pelas Normas Internacionais do Trabalho sobre a Reabilitação Profissional e Emprego de Pessoas Portadoras de Deficiência da Organização Internacional do Trabalho, em 2001 (Organização Internacional do Trabalho, 2001), Convenção Internacional sobre os Direitos das Pessoas com Deficiência da Organização das Nações Unidas, em 2007 (Organização das Naçóes Unidas, 2007), e pelo Relatório Mundial sobre a Deficiência, publicado em 2011, pela Organização Mundial da Saúde (2011).

Este cenário reconhece os direitos das pessoas com deficiência e reforça a necessidade de açóes voltadas para maior inclusão desta população, com garantia de direitos, equiparação de oportunidades e possibilidade de ampliação da participação social, incluindo no trabalho (Organização Internacional do Trabalho, 2001). Neste sentido, o estabelecimento de acordos e normas internacionais, como a Convenção no 159/83 da Organização Internacional do Trabalho (OIT), são importantes mecanismos regulatórios que reforçam a importância do emprego adequado e a possibilidade de integração ou reintegração das pessoas com deficiência na sociedade (Organização Internacional do Trabalho, 2001). O Brasil é um dos países signatários desta convenção da OIT, o que torna suas deliberaçóes com valor de decreto (Brasil, 1991a). Outra política com caráter internacional é a Convenção Internacional sobre os Direitos das Pessoas com Deficiência da Organização das Naçóes Unidas (ONU), que trata de trabalho e emprego reconhecendo ambos como direito das pessoas com deficiência (Organização das Nações Unidas, 2007). O Brasil também é subscritor desta convenção, a qual fundamenta parte da legislação nacional, como o Estatuto da Pessoa com Deficiência (Brasil, 2015).

No âmbito nacional, o arcabouço jurídico brasileiro para equiparação de oportunidade com o estabelecimento dos direitos e garantias fundamentais para todas as pessoas, com e sem deficiência, foi efetivado com a promulgação da Constituição Federal (CF), no ano de 1988 (Brasil, 2006); pela Lei de Cotas (Lei no 8.213), de 1991 (Brasil, 1991b); e pela Lei no 13.146, de 2015, que institui o Estatuto da Pessoa com Deficiência (Brasil, 2015). Em relação à Constituição Federal, na descrição dos artigos sobre os direitos sociais, há a proibição de qualquer tipo de discriminação de forma de remuneração e processo de admissão dos trabalhadores com deficiência. Já a Lei no 8.213 de 1991, em seu artigo 93, estabelece um sistema de cotas que determina percentuais mínimos de trabalhadores com algum tipo de deficiência para as empresas com 100 ou mais funcionários (Brasil, 1991b). Em acréscimo, o Estatuto da Pessoa com Deficiência reforça o dever do Estado em assegurar à pessoa com deficiência a efetivação do direito ao trabalho (Brasil, 2015).

Desta forma, a contratação de pessoas com deficiência pelo mercado de trabalho é um fenômeno que vem incorporando mudanças da legislação subsidiadas por políticas de valorização das diferenças e que buscam reconhecer todos como cidadãos de direitos e deveres. A legislação brasileira veda qualquer restrição ao trabalho da pessoa com deficiência, inclusive nas etapas de recrutamento, seleção, contratação e admissão (Brasil, 2015). No entanto, apesar do amparo legal, observa-se dificuldade de empregabilidade entre pessoas com deficiência. De acordo com dados da Relação Anual de Informaçóes Sociais (RAIS), em 2017, apenas 54\% do total de vagas 
disponíveis no mercado de trabalho para pessoas com deficiência foram preenchidas no Brasil (Brasil, 2017).

O Estado de Minas Gerais é dividido em 13 macrorregióes assistenciais e administrativas, sendo a região do Triângulo Mineiro composta por duas macrorregionais: Triângulo Norte, com sede em Uberlândia, e Triângulo Sul, com sede em Uberaba (Minas Gerais, 2013). Oficialmente, só existe um estudo com dados publicados sobre preenchimento de vagas para pessoas com deficiência no Município de Uberlândia. Assim, dados de Uberlândia/MG, localizada na regiáo do Triângulo Mineiro, mostram que apenas $28,57 \%$ das vagas ofertadas para pessoas com deficiência foram preenchidas no ano de 2009 (Souza \& Kamimura, 2010). As vagas de emprego ofertadas no mercado de trabalho, suas características e a disponibilização de informaçóes se constituem em um elo entre a pessoa com deficiência e a oportunidade de efetivação do processo de inclusão no trabalho.

Neste contexto, esta pesquisa analisou e descreveu as vagas de emprego disponibilizadas para pessoas com deficiência, no período de um ano.

\section{Método}

Estudo quantitativo, do tipo longitudinal e descritivo (Gil, 2002), aprovado pelo Comitê de Ética em Pesquisa (CAAE 37058314.2.0000.5154) da Universidade Federal do Triângulo Mineiro. Foram analisadas as vagas de emprego ofertadas para pessoas com deficiência disponíveis online nos sítios eletrônicos das agências de empregos Sistema Nacional de Emprego (SINE), Vagas.com, Jornal da Manhã e Jornal de Uberaba. Esses locais fazem a intermediação de mão de obra e publicitam as vagas de emprego para a população da Microrregiáo de Uberaba, localizada na Macrorregião do Triângulo Sul, que pertence à Região do Triângulo Mineiro no Estado de Minas Gerais.

A agência Sistema Nacional de Emprego (SINE) é um órgão do Governo Federal, coordenado pelo Ministério do Trabalho e Emprego, por intermédio da Secretaria de Políticas de Emprego e Salário (Borges, 2003). O Vagas.com é um dos maiores sites de carreira do Brasil, no qual profissionais de todas as áreas e níveis de escolaridade e formação têm acesso a oportunidades de emprego divulgadas por diversas empresas do Brasil (Vagas.com, 2017). As mídias de comunicação em massa, Jornal da Manhã e Jornal de Uberaba, possuem classificados em seus noticiários que publicitam as vagas de emprego disponíveis na Microrregiáo de Uberaba/MG, tanto no formato impresso como online.

As informaçóes sobre as vagas de emprego para pessoas com deficiência foram coletadas nos sítios eletrônicos mencionados. Todas as vagas analisadas são ofertas de emprego cadastradas nestes locais de busca e disponíveis publicamente para acesso livre e gratuito de todo trabalhador, com ou sem deficiência. A escolha por coletar dados disponíveis online se deu pela facilidade de acesso da pessoa com deficiência, que não precisaria se deslocar para obter as informaçóes sobre a vaga de emprego, uma vez que as informaçóes apresentadas online são as mesmas disponibilizadas em material impresso. Além disso, a redução dos gastos financeiros, a acessibilidade já presente nos sites visitados e as versóes destes sítios eletrônicos para dispositivos móveis, como celular, são vantagens adicionais que justificam o uso de informaçóes online. 
Diante da variedade de definiçóes e conceitos apresentados na literatura sobre o constructo "deficiência" e para fins de padronização, este estudo utilizou como conceito de deficiência a definição apresentada pela OMS na CIF (Organização Mundial da Saúde, 2003), assim como os dados e aspectos metodológicos de análise estabelecidos no Censo 2010 (Instituto Brasileiro de Geografia e Estatística, 2015). As buscas das vagas de emprego foram realizadas semanalmente, durante o período de 01 de outubro de 2014 a 31 de outubro de 2015, toda segunda-feira, com exceção da semana do dia 01 de outubro de 2014 em que a coleta foi realizada em uma quarta-feira. No momento da coleta, dois pesquisadores analisavam todos os anúncios de emprego ofertados nos sítios eletrônicos e selecionavam as que indicavam serem vagas específicas para pessoas com deficiência. Foram coletadas todas as informações disponíveis no anúncio das vagas, como número de vagas ofertadas; cargo/função; salário; setor da economia e tipo de empresa, por exemplo; e exigências para o preenchimento da vaga, como escolaridade, faixa etária e sexo, por exemplo. Essas informaçóes eram armazenadas em uma planilha do programa Excel for Windows exatamente da mesma forma como estavam apresentadas nos anúncios.

Os dados foram submetidos à análise estatística descritiva em termos de medidas de tendência central, medidas de variabilidade e frequência. Essa análise foi realizada no programa estatístico SPSS, versão 20.0, e os gráficos foram construídos no programa Excel for Windows.

\section{Resultados}

Foram totalizadas 57 semanas de coleta de informaçóes sobre as vagas de emprego ofertadas para pessoas com deficiência. Neste período, por 11 dias não foram publicadas vagas para pessoas com deficiência em quaisquer dos locais de buscas. Ao longo do período de coleta das informaçôes, detectou-se a oferta de 112 vagas de emprego específicas para pessoas com deficiência, sendo 25 (22,32\%) anúncios referentes a vagas reabertas, o que totaliza uma oferta real de 87 vagas em um ano. Estas 87 vagas ficaram disponíveis nos endereços eletrônicos dos sítios investigados por, em média, 10,10 dias ( $\mathrm{DP}=10,53)$.

Em relação aos sites de buscas, a agência de emprego SINE foi a que apresentou o maior percentual de vagas ofertadas (58\%) durante a pesquisa. Do total das vagas analisadas, $17,9 \%$ não identificaram o sexo para seu preenchimento e $74,1 \%$ eram destinadas para mulheres e homens. Sobre a faixa etária exigida, $84,8 \%$ não identificaram este requisito e $15,2 \%$ das vagas eram destinadas a pessoas com idade variando entre 18 e 50 anos. Quanto à escolaridade, $18,8 \%$ das vagas não identificavam o nível de escolaridade exigida, 22,3\% exigiam Ensino Fundamental incompleto e 39,3\% Ensino Médio Completo. Quando analisada a qualificação exigida para preenchimento das vagas, 33,9\% não descreviam qualquer informação sobre a qualificação necessária para preencher a vaga; 19,6\% dos anúncios descreviam que o cargo não exigia qualificação para seu preenchimento; $32,2 \%$ descreviam a necessidade de experiência na área de, no mínimo, seis meses; e 14,3\% exigiam experiência prévia na área da vaga sem especificar o tempo. A Tabela 1 apresenta a descrição completa das informações sobre agência, sexo, faixa etária, escolaridade e exigência/qualificação. 
Tabela 1. Descriçẫo das informaçôes completas sobre agência, faixa etária, gênero, escolaridade e exigência de experiência/qualificação das vagas ofertadas para pessoas com deficiência $(n=112)$. Outubro/2014 a Outubro/2015. Microrregião de Uberaba/MG.

\begin{tabular}{|c|c|c|}
\hline Variáveis & Frequência & Porcentagem (\%) \\
\hline \multicolumn{3}{|l|}{ Agências } \\
\hline Sine & 65 & 58,0 \\
\hline Vagas.com & 26 & 23,2 \\
\hline Jornal da Manhã & 12 & 10,7 \\
\hline Jornal de Uberaba & 09 & 8,1 \\
\hline \multicolumn{3}{|l|}{ Faixa Etária } \\
\hline Não identificado & 95 & 84,8 \\
\hline Até 30 anos & 02 & 1,8 \\
\hline Até 40 anos & 06 & 5,4 \\
\hline Até 50 anos & 05 & 4,5 \\
\hline Maior de 18 anos & 04 & 3,5 \\
\hline \multicolumn{3}{|l|}{ Sexo } \\
\hline Não identificado & 20 & 17,9 \\
\hline Feminino & 02 & 1,8 \\
\hline Masculino & 07 & 6,2 \\
\hline Ambos & 83 & 74,1 \\
\hline \multicolumn{3}{|l|}{ Escolaridade } \\
\hline Não identificado & 21 & 18,8 \\
\hline Náo exige & 01 & 0,9 \\
\hline Ensino Fundamental Incompleto & 25 & 22,3 \\
\hline Ensino Fundamental Completo & 11 & 9,8 \\
\hline Ensino Médio Incompleto & 01 & 0,9 \\
\hline Ensino Médio Completo & 44 & 39,3 \\
\hline Curso Técnico & 06 & 5,3 \\
\hline Curso Superior & 02 & 1,8 \\
\hline Pós-Graduação & 01 & 0,9 \\
\hline \multicolumn{3}{|l|}{ Exigência/Qualificação } \\
\hline Não identificada & 38 & 33,9 \\
\hline Não exigia nenhuma qualificação & 22 & 19,6 \\
\hline Experiência de, no mínimo, 6 meses & 36 & 32,2 \\
\hline Experiência específica para a vaga sem exigência de tempo & 16 & 14,3 \\
\hline
\end{tabular}

A maioria dos anúncios $(51,8 \%)$ não descreveu o segmento econômico para o qual a vaga era destinada. Em relação aos cargos e funçóes, identificou-se uma maior oferta para vagas de Auxiliar Administrativo (17,9\%), Caixa/Recepcionista/Atendente $(10,7 \%)$ e Auxiliar de Linha de Produção (6,3\%). As Figuras 1 e 2 apresentam a distribuição completa das vagas por setor econômico e por cargos e funçóes. A maioria das vagas $(94,6 \%)$ não restringiu o tipo específico de deficiência (Tabela 2). 


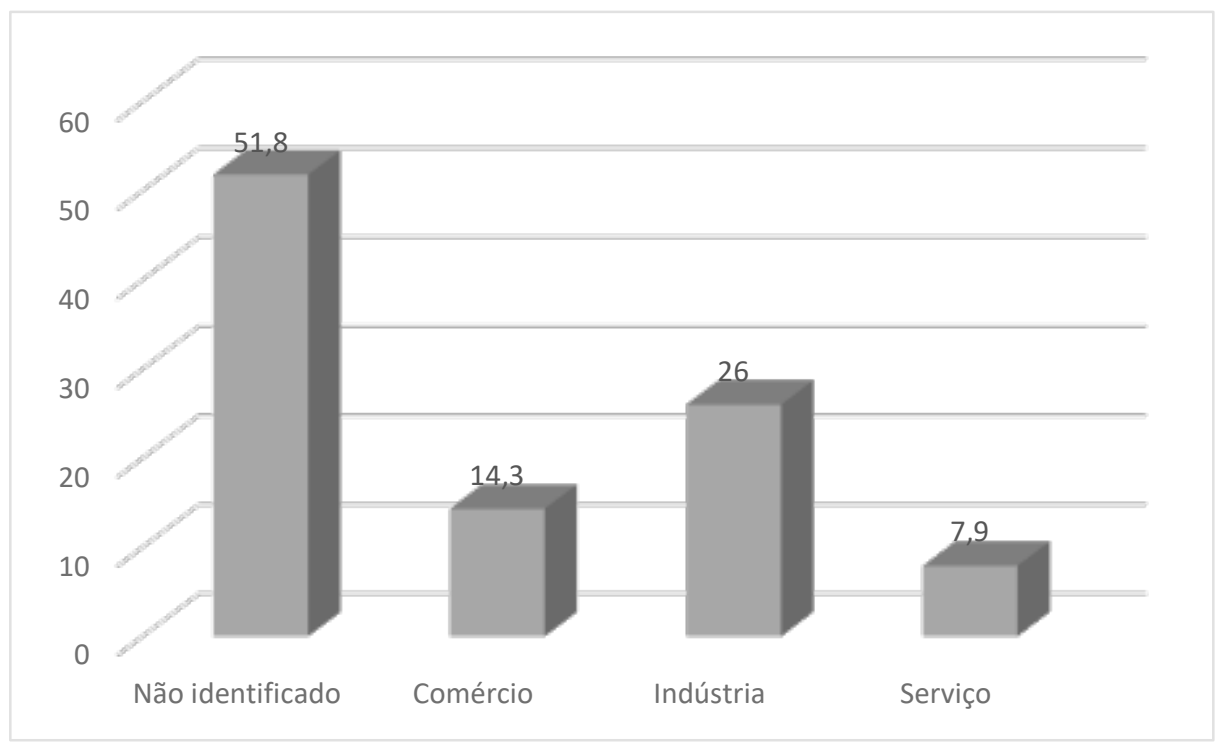

Figura 1. Percentual de vagas ofertadas a pessoas com deficiência distribuídas por segmento econômico/setor de atividade. $(n=112)$. Outubro/2014 a Outubro/2015. Microrregião de Uberaba/MG.

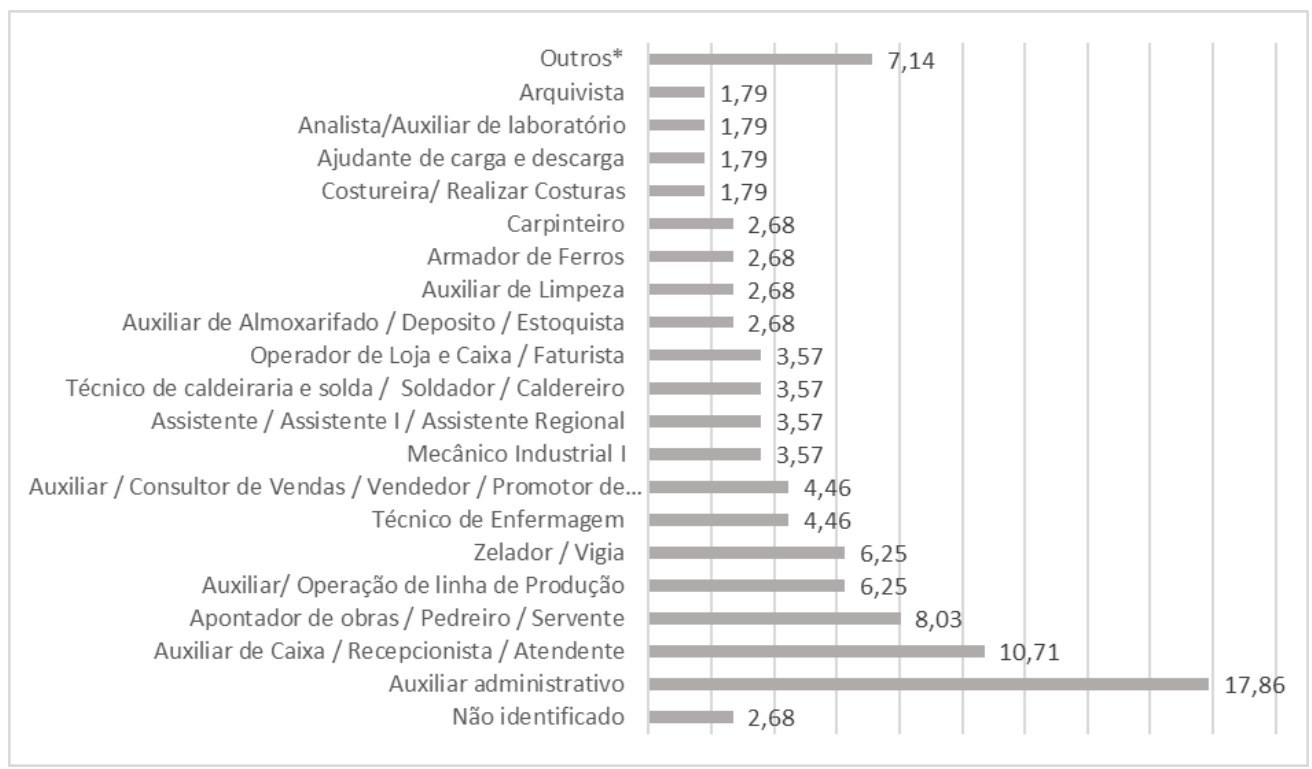

Figura 2. Distribuição das vagas ofertadas a pessoas com deficiência de acordo com os cargos e funçôes das vagas. ( $\mathrm{n}=112$ ). Outubro/2014 a Outubro/2015. Microrregião de Uberaba/MG. *Outros: Auxiliar de compras, Auxiliar de orientação educacional, Auxiliar de produção predial,

Colaborador, Coordenador de planejamento e controle de produção, Jardineiro, Técnico de mecânica e Técnico em química. 
Tabela 2. Descrição das exigências quanto ao tipo de deficiência das vagas ofertadas a pessoas com deficiência. (n=112). Outubro/2014 a Outubro/2015. Microrregião de Uberaba/MG.

\begin{tabular}{ccc}
\hline $\begin{array}{c}\text { Exigências quanto ao tipo de deficiência como requisito para } \\
\text { preenchimento da vaga }\end{array}$ & Frequência & Porcentagem (\%) \\
\hline Náo identificado & 106 & 94,6 \\
\hline "Não encaminhar cadeirante, empresa não adaptada" & 02 & 1,8 \\
\hline "Náo enviar cadeirantes e deficientes visuais" & 01 & 0,9 \\
\hline "Deficiente visual e auditivo" & 02 & 1,8 \\
\hline "Deficiência que permita o normal desempenho das atividades" & 01 & 0,9 \\
\hline
\end{tabular}

${ }^{1}$ As categorias de exigência quanto ao tipo de deficiência apresentadas nesta tabela foram transcritas exatamente da mesma forma como constavam nos anúncios das vagas analisadas.

Em relação ao salário oferecido, a média apresentada foi de $\mathrm{R} \$ 1.049,28$ $(\mathrm{DP}=301,36)$ reais, o que corresponde a menos de 1,5 salários mínimos. Além do salário, 64,3\% das vagas analisadas também informavam o recebimento de benefícios para o trabalhador, como auxílio alimentação, vale transporte e plano de saúde. As demais 40 vagas $(35,7 \%)$ não identificavam nenhuma informação sobre benefícios.

\section{Discussáo}

Durante o período de um ano, realizou-se a análise de todas as vagas de emprego disponíveis online para pessoas com deficiência da Microrregião de Uberaba/MG, disponíveis nos sítios online incluídos neste estudo. Em sua maioria, as vagas ofertadas não disponibilizavam informaçóes importantes, como requisitos para assumir a vaga, empresa, ramo da economia e cargo a ser desempenhado. Houve predominância de funções que exigiam pouca qualificação e ofereciam média salarial baixa. A Microrregião de Uberaba, localizada na Macrorregião do Triângulo Sul, é composta por oito municípios com população total de 369.920 habitantes e se constitui no sexto maior polo econômico e sétimo maior gerador de empregos formais do Estado de Minas Gerais (Instituto Brasileiro de Geografia e Estatística, 2015). De acordo com o Censo de 2010, o número estimado de pessoas com deficiência é cerca de $10 \%$ desta população, o que corresponde a aproximadamente 36.992 pessoas (Instituto Brasileiro de Geografia e Estatística, 2015).

No estado de Minas Gerais, de acordo com dados do Censo 2010, das 4.432.186 pessoas com deficiência, 3.104.061 estão em idade economicamente ativa e, destas, apenas 1.608.649 estáo empregadas, o que corresponde a 51,82\% do total de pessoas com deficiência em idade produtiva (Instituto Brasileiro de Geografia e Estatística, 2010a). A baixa oferta de vagas oferecidas no período analisado durante esta pesquisa aponta para esta limitação. Considerando o número estimado de pessoas com deficiência em idade economicamente ativa na regiáo investigada, 20.406 pessoas (Instituto Brasileiro de Geografia e Estatística, 2010b), e a oferta de 112 vagas, observa-se uma relação de aproximadamente 182,2 pessoas para cada vaga ofertada. Como documentado por outros estudos, tanto em países desenvolvidos quanto em desenvolvimento, pessoas com deficiência em idade de trabalhar apresentam baixas taxas de empregabilidade e taxas mais altas de desemprego do que pessoas sem 
deficiências (Ramachandra et al., 2017; Verhoef et al., 2014; Cramm et al., 2013; Baptista \& Silva, 2011).

Apesar do crescimento na oferta de empregos formais para pessoas com deficiência, dados nacionais e estaduais recentes corroboram esta baixa empregabilidade da população com deficiência (Brasil, 2017). Em 2017, 441.339 mil vínculos foram declarados como de pessoas com deficiência, representando 0,95\% do total dos vínculos empregatícios no Brasil (Brasil, 2017). Já em Minas Gerais, esse percentual corresponde a apenas $0,61 \%$ dos vínculos para pessoas com deficiência, enquanto os valores das taxas de empregabilidade da população geral chegam a $60,9 \%$ para o estado e a $70,46 \%$ na cidade de Uberaba (Brasil, 2017). Alguns estudos mostram avanços na ampliação de oferta de vagas de emprego para pessoas com deficiência (Organização Mundial da Saúde, 2011) e diversos países (como Portugal, Brasil, Espanha, Alemanha e Áustria) possuem políticas de incentivo ao trabalho que estimulam o acesso de pessoas com deficiência (Brasil, 1991a, 2015). Esses incentivos englobam desde a reserva formal de números de vagas em relação ao número total de trabalhadores ao incentivo fiscal e contribuições da empresa, para fomentar mecanismos de profissionalização (Brasil, 1991b).

Embora a Microrregião de Uberaba seja o sétimo maior gerador de empregos formais do Estado de Minas Gerais (Instituto Brasileiro de Geografia e Estatística, 2015), ao longo de um ano foram identificadas apenas 112 vagas destinadas a pessoas com deficiência. A Lei $\mathrm{n}^{\mathrm{0}}$ 8.213/91 estabelece a obrigatoriedade de reserva de vagas para pessoa com deficiência em empresas com mais de 100 vínculos ativos, o que resultaria em um total de 112.348 cotas a serem cumpridas no Estado de Minas Gerais (Brasil, 2017). No entanto, de acordo com a RAIS, 83.417 vagas não foram disponibilizadas para pessoas com deficiência (Brasil, 2017), isto é, apenas 28.931 vagas foram disponibilizadas para pessoas com deficiência em todo o Estado de Minas Gerais. Esse dado mostra que $74,25 \%$ das cotas não foram disponibilizadas por empresas com mais de 100 vínculos ativos, reforçando indícios da baixa oferta de vagas para pessoas com deficiência e da baixa adesão das empresas às orientações da Lei de Cotas (Brasil, 1991b).

$\mathrm{O}$ atual cenário econômico e social brasileiro e os constantes circuitos de desigualdade e fragilidade que caracterizam o cotidiano das pessoas com deficiência, conduzem para o reforço de barreiras (como a física e a atitudinal) que limitam a garantia de oportunidade e a consequente inserção das pessoas com deficiência no mercado de trabalho formal. Alguns fatores podem influenciar as características das vagas de emprego ofertadas para pessoas com deficiência, como a baixa escolaridade e/ou baixo nível de qualificação profissional deste trabalhador (Lorenzo \& Silva, 2017); a dificuldade recorrente de inserção social e de estabelecimento de vínculos além dos paternos; a falta de acessibilidade física das empresas; a presença de barreiras atitudinais que reforçam o desconhecimento do potencial das pessoas com deficiência; e o preconceito que, apesar de ser combatido constantemente por meio de políticas de educação e veiculação nas grandes mídias, ainda é um forte impeditivo de uma inclusão social efetiva (Bahia \& Santos, 2009). Sempertegui (2015) caracteriza estas dificuldades como barreiras culturais, isto é, um conjunto de representaçóes sociais, ideias e concepçóes sobre a empregabilidade, a deficiência, as pessoas definidas como deficientes e suas possibilidades de empregabilidade, arraigadas no imaginário coletivo. 
Assim, o processo de integração de trabalhadores com deficiência é dificultado, entre outros fatores, pelo descrédito em relação à capacidade para o exercício das funções a eles atribuídas (Carvalho, 2009; Neves-Silva et al., 2015). O desconhecimento por parte dos empregadores sobre a capacidade produtiva das pessoas com deficiência é um dos fatores responsáveis pela não contratação desses trabalhadores relacionados à crença de que a pessoa com deficiência é incapacitada para as atividades laborais (Hammes \& Nuernberg, 2014). O preconceito está associado à falta de informação por parte das empresas sobre as potencialidades dessas pessoas, uma vez que não se conhece suas habilidades, capacidades e reais limitaçóes, dificultando a contratação ou mesmo a permanência destas no trabalho (Neves-Silva et al., 2015; Sempertegui, 2015; Ramachandra et al., 2017).

Para Hammes \& Nuernberg (2014), algumas empresas disponibilizam vagas com rigorosas especificidades, de difícil preenchimento e sem flexibilização. Este é um importante aspecto associado à baixa empregabilidade de pessoas com deficiência, apontado como uma estratégia da empresa, a qual impossibilita o preenchimento da oferta frente à falta de profissionais capacitados no mercado que se ajustem ao perfil declarado (Hammes \& Nuernberg, 2014). Essa situação pode ser aplicada na análise das vagas que exigiam "Deficiência que permita o normal desempenho das atividades". Essa exigência mostra uma compreensão equivocada por parte dos empregadores sobre a deficiência sem alterações funcionais, o que implicaria na não necessidade de adaptação do posto e/ou do processo de trabalho pela empresa. Este contexto ilustra a ausência velada da colocação desta parcela da população no campo de trabalho e exclui pessoas com deficiência e possíveis limitaçóes funcionais, na maioria das vezes, da oportunidade de envolvimento no trabalho. Essa situação exemplifica uma incompreensão sobre o que é limitação, incapacidade e deficiência; e como essas características deveriam ser levadas em consideração para que de fato ocorresse equiparação de oportunidade e inclusão social.

A Lei de Cotas, ao estipular que as vagas a serem ocupadas por pessoas com deficiência devem ser cumpridas apenas nas empresas com cem ou mais empregados, define um limite matemático para sua execução (García, 2014). Se for cumprida na íntegra, cerca de 900 mil vagas seriam preenchidas por este segmento populacional; número insuficiente, dada a proporção de $24,94 \%$ de pessoas com deficiência em idade produtiva no Brasil (Brasil, 2012). Neste contexto, a discussão de propostas para ampliar o perfil das empresas obrigadas a cumprir as cotas poderia aumentar significativamente o número de vagas potenciais de emprego oferecidas às pessoas com deficiência. Organizaçóes não governamentais ou o Sistema S (SENAI, SENAC ou SENACOP, dentre outros) são possíveis estratégias para melhorar a capacitação dos trabalhadores com deficiência (Borges, 2003). A vaga ofertada pode ser atrelada a programas de formação profissional, o que permitiria que as empresas flexibilizassem os requisitos para o preenchimento das vagas e, ao mesmo tempo, promovesse o desenvolvimento de açóes verdadeiramente inclusivas e com respeito aos princípios constitucionais de igualdade e valor social do trabalho.

Serviços profissionais de reabilitação e emprego, como capacitação profissional, aconselhamento, assistência na procura de emprego e colocação são opçóes que podem auxiliar e/ou facilitar a inclusão de pessoas com deficiência, especialmente no mercado de trabalho. Neste sentido, de acordo com a European Union of Supported 
Employment (EUSE), a proposta de política pública do Emprego Apoiado tem por objetivo assegurar que a pessoa com deficiência encontre e mantenha um emprego remunerado em empresas do mercado formal de trabalho (European Union of Supported Employment, 2019). No Brasil, o Emprego Apoiado consiste em uma metodologia que oferece suporte aos processos de inclusão no trabalho com base em ações de assessoria, orientação e acompanhamento personalizado, dentro e fora do local de trabalho, realizadas por preparadores laborais e profissionais especializados (Betti, 2014).

A agência de emprego SINE foi a que apresentou o maior percentual de vagas ofertadas durante a pesquisa, porém, $22,32 \%$ das vagas ofertadas por todas as agências não foram preenchidas, sendo reabertas. Outras cidades também enfrentam dificuldades em preencher as vagas de emprego destinadas a pessoas com deficiência. Em Uberlândia/MG, no ano de 2009 , apenas $28,57 \%$ das vagas ofertadas para pessoas com deficiência foram preenchidas (Souza \& Kamimura, 2010), e em São Carlos/SP, em 2013, 48,7\% das vagas disponíveis foram ocupadas (Simonelli et al., 2013). O modelo de Emprego Apoiado tem-se revelado uma forte proposta associada à preparação vocacional e progressiva independência do indivíduo em relaçáo ao desempenho laboral (Ramachandra et al., 2017). Esta abordagem, quando empregada e apoiada por políticas públicas, pode oferecer estratégias para aumentar a empregabilidade de pessoas com deficiência e diminuir o número de vagas não preenchidas. A intervenção com Emprego Apoiado centra em uma abordagem em que o indivíduo é formado para um posto de trabalho, em um processo que considera suas competências básicas (Betti, 2014; European Union of Supported Employment, 2019). De acordo com a literatura, o modelo de Emprego Apoiado tem mostrado evidências importantes no planejamento do trabalho baseado nas necessidades específicas de cada pessoa com deficiência (Ramachandra et al., 2017).

Ainda, estudos que analisam as dificuldades para o preenchimento das vagas para pessoas com deficiência apontam a falta de acessibilidade como um dos principais obstáculos (Hammes \& Nuernberg, 2014; Neves-Silva et al., 2015). Apesar de a maioria das vagas analisadas não mencionar limitaçóes quanto ao tipo de deficiência, $5,4 \%$ das vagas claramente restringem o acesso de um amplo número de pessoas com deficiência e 1,8\% declaram que a empresa não é adaptada. Esses dados revelam a falta de informação das empresas acerca do arcabouço das normativas legais do governo; constituem-se em barreiras para a acessibilidade e são atitudes discriminatórias que explicitamente limitam o preenchimento das vagas por pessoas com deficiência. A ausência de acessibilidade arquitetônica, comunicacional, metodológica, instrumental, programática, atitudinal e tecnológica impóe barreiras que impedem a efetiva inclusão para se ter autonomia e independência das pessoas com deficiência, impondo restriçóes para sua efetiva participação no ambiente do trabalho. Como resultado, há dificuldades para trabalhar em igualdade de oportunidades com os demais trabalhadores e de maneira mais produtiva (Neves-Silva et al., 2015).

Além das questóes relacionadas à garantia de acessibilidade arquitetônica nas edificaçóes, Simonelli \& Camarotto (2011) sugerem que as empresas realizem um diagnóstico do local de trabalho e das adaptações necessárias para que o indivíduo possa trabalhar de maneira adequada. Esta ação pode potencializar a capacidade para o trabalho da pessoa com deficiência e permitir à empresa acolher este trabalhador de 
maneira mais efetiva garantindo, assim, sua permanência no emprego. Este é um modelo de inclusão de pessoas com deficiência no trabalho exigido desde 2015 pelo Estatuto da Pessoa com Deficiência (Brasil, 2015), que engloba acessibilidade arquitetônica, atitudinal e política das empresas em relação aos seus trabalhadores. Para Ramachandra et al. (2017), as experiências e preocupaçóes das pessoas com deficiência precisam ser documentadas e compartilhadas com potenciais empregadores para sensibilizá-los em relação às necessidades destas pessoas no local de trabalho. Neste mesmo estudo, acesso físico e no local de trabalho, comunicação, atitude das pessoas, discriminação, assédio no local de trabalho e a disponibilidade de informação foram destacados como barreiras críticas para a manutençấo do emprego de pessoas com deficiência (Ramachandra et al., 2017).

A presença de um profissional habilitado, como o terapeuta ocupacional, pode auxiliar na definição das características das vagas até na adaptação do funcionário no cargo, sendo descrita na literatura como fundamental para êxito da contratação e manutenção do trabalhador com deficiência no emprego (Lorenzo \& Silva, 2017). Neste contexto, destaca-se a importância do envolvimento do terapeuta ocupacional nos processos de inclusão da pessoa com deficiência no mercado de trabalho. Este profissional integra diferentes áreas da saúde do trabalhador, bem como setores de recursos humanos, e pode desenvolver açóes voltadas para avaliação do perfil ocupacional; análise, intervenção e adaptação de postos de trabalho e do processo de trabalho; percepção e prevenção de riscos de acidentes do trabalho e adoecimentos; avaliaçóes funcionais e dos aspectos psíquicos do trabalho e programas de inclusão e/ou realocação de trabalhadores com restriçóes ou deficiência (Lancman \& Ghirardi, 2004; American Occupational Therapy Association, 2014). Desta forma, sugere-se outras investigaçóes científicas sobre o conhecimento da profissão por parte dos empregadores e o quanto terapeutas ocupacionais podem auxiliar o processo de engajamento de pessoas com deficiência no mercado de trabalho.

A iniciativa para a inserção de profissionais para auxiliar na equiparação de oportunidades e acessibilidade, em especial do terapeuta ocupacional, amplia as possibilidades de uma inclusão adequada e efetiva para identificar postos de trabalho que potencialmente poderiam ser ocupados por pessoas com deficiência. Sem as adaptaçóes ou alteraçóes na estrutura arquitetônica; nas atitudes de empregadores, chefia e colegas; sem políticas da empresa sobre o emprego de pessoas com deficiência; e com a falta de propostas de ações que permitam a real análise das habilidades necessárias para a realização das atividades de trabalho, pessoas com deficiência continuarão a ter dificuldades de contratação pelas empresas. Por outro lado, aqueles que conseguirem assumir as vagas poderão ficar isolados dos demais trabalhadores, com pouca cooperação mútua e suporte no local de trabalho, além de enfrentarem barreiras para desempenhar as tarefas sob suas responsabilidades.

Em relação às informações disponíveis nos anúncios de emprego, observou-se que a maioria das vagas analisadas não apresentou descrições mínimas necessárias sobre os critérios e requisitos para seu preenchimento. A falta desses dados restringe o acesso da pessoa com deficiência a informaçóes essenciais sobre as vagas disponíveis, como cargo e função, salário, setor da economia e tipo de empresa, e exigências para o preenchimento da vaga como escolaridade, faixa etária e sexo, por exemplo. De acordo com a Controladoria Geral da União (CDU) (Brasil, 2011), todos têm direito de 
receber dos órgãos públicos ou privados informaçóes de seu interesse particular ou de interesse coletivo ou geral. Os mecanismos comunicacionais têm que se adaptar, tornando a informação cada vez mais acessível para todos. O acesso a informaçóes constitui-se em um dos fundamentos para a consolidação da democracia (Brasil, 2011). A falta de acesso à informação, ou mesmo a não disponibilização de informaçóes importantes, reforça a exclusão e a ausência de equiparação de oportunidades.

Em relação à escolaridade, tipos de função e média salarial, observou-se uma predominância de vagas de emprego relacionadas a funçóes que exigiam baixa qualificação. Este perfil de vaga de emprego para pessoas com deficiência já é descrito em outros estudos que analisam a inserção desta população no mercado formal (Coelho et al., 2014; Leão \& Silva, 2012; Simonelli \& Camarotto, 2011; Baptista \& Silva, 2011). A maioria das empresas não acredita que possam existir pessoas com deficiência qualificadas, com isso, as vagas ofertadas se restringem a trabalhos operacionais (Neves-Silva et al., 2015). Além disso, a falta de qualificação profissional está diretamente relacionada com a remuneraçáo salarial. Assim, as pessoas com deficiência parecem não estar empregadas de acordo com o potencial que possuem, e são conduzidas a ocupar posiçóes hierarquicamente inferiores e de menores salários, sub-representados no mercado de trabalho. Igualmente, essas pessoas têm se concentrado em ocupaçóes mais simples, isto é, com exigência de menor escolaridade e qualificação técnico-profissional, e com menor remuneração (García, 2014; Toldrá et al., 2010).

Dados da Secretaria Nacional de Promoção dos Direitos da Pessoa com Deficiência apontam que apenas $1,2 \%$ das crianças e adolescentes matriculados na educação básica possuem algum tipo de deficiência (Brasil, 2012). Quando analisamos a população brasileira com idade de 0 a 18 anos com alguma deficiência, 70,64\% estão fora da escola (Brasil, 2012). Estas informaçóes colaboram para justificar o atual cenário de inserção das pessoas com deficiência em diversos setores da sociedade, entre eles, no mercado de trabalho, estreitando relação entre desigualdades sociais e incapacidades. Neste sentido, a discussão da inclusão da pessoa com deficiência no mercado de trabalho requer uma abordagem que integre as políticas sociais que incluem educação, saúde, renda, emprego e habitação.

O caráter descritivo deste estudo e o levantamento de dados disponíveis apenas em mídias online são limitaçóes que devem ser consideradas e discutidas. O delineamento descritivo não permite análises inferenciais e a coleta de dados online limita o universo amostral deste estudo. No entanto, as características das vagas apresentadas neste estudo se assemelham a outras investigaçóes que também analisaram emprego para pessoas com deficiência. Além disso, não foram encontradas investigaçôes sobre a forma com que as informaçóes da vaga de emprego são disponibilizadas e apresentadas para a pessoa com deficiência. Essa forma de apresentação da informação sobre a vaga é um elo entre a pessoa com deficiência e a oportunidade de efetivação de direitos que subsidiam o processo de inclusão no trabalho. As observaçóes longitudinais também são uma estratégia metodológica de coleta de dados que permite seguimento de um fenômeno com sequência lógica temporal, ainda pouco exploradas na literatura nacional da terapia ocupacional. Assim, este estudo ganha relevância quando analisa as características das vagas de emprego para pessoas com deficiência ao longo de um 
período de tempo e sinaliza desafios para a real inserção da pessoa com deficiência no mercado de trabalho, desvelando informaçóes que podem subsidiar as açóes do terapeuta ocupacional.

Neste contexto, é necessário um conjunto de ações interdisciplinares e intersetoriais de diferentes atores em busca de igualdade de oportunidades para as pessoas com deficiência em diferentes áreas da vida, incluindo no trabalho. O desenvolvimento de propostas voltadas para políticas e programas sociais, como a criação de cursos de capacitação desenvolvidos pelas próprias empresas, treinamento continuado e reabilitação vocacional (Organização Mundial da Saúde, 2011) são importantes para a inclusão da pessoa com deficiência no mercado de trabalho e para um aumento do percentual de preenchimento das vagas. Neste contexto, a proposta da política pública de emprego apoiado, já apresentada aqui, constitui-se em uma alternativa importante para a maior equiparação de oportunidades e efetivação da empregabilidade de pessoas com deficiência. A inclusão no trabalho comporta um conjunto de açóes educativas focais e integradas que exigem mudanças na sociedade em âmbito geral, na (re)estruturação dos sistemas de ensino de forma integrada ao mercado de trabalho, na sensibilização e exigência para que as empresas cumpram com suas obrigaçóes e na definição de ações governamentais direcionadas à criação de serviços de capacitação profissional da pessoa com deficiência (Lorenzo \& Silva, 2017).

\section{Conclusáo}

A descrição do perfil das vagas de emprego destinadas a pessoas com deficiência mostrou baixa oferta de vagas nas agências de emprego e jornais locais da Microrregiáo de Uberaba/MG, falta de informaçóes essenciais sobre as vagas, como cargo ou funçáo, remuneração, local/empresa de trabalho e exigências, como escolaridade e experiência prévia. Os resultados corroboram um perfil de vagas historicamente ofertadas a pessoas com deficiência, caracterizadas principalmente por funçôes que exigem nenhuma ou pouca qualificação e oferecem média salarial baixa. Soma-se a este cenário a ausência de acessibilidade e/ou adaptação das empresas observadas por meio de restriçóes impostas para o preenchimento de algumas vagas.

A formação e a capacitação desse trabalhador são fatores determinantes para a inclusão de pessoas com deficiência em cargos e funçóes mais qualificadas. O desenvolvimento de projetos que busquem auxiliar a empresa e acompanhar o trabalhador durante o processo de contratação é uma importante estratégia para aumentar a inserção da pessoa com deficiência no mercado de trabalho, e uma lacuna que pode ser preenchida pelo terapeuta ocupacional. Assim, sugere-se a ampliaçáo da discussão do Emprego Apoiado como principal estratégia metodológica para inserção de pessoas com deficiência em postos de trabalho.

Os resultados também apontam para falhas no sistema de informação sobre as vagas ofertadas que precisam ser corrigidas, possibilitando acessibilidade das pessoas com deficiência aos meios de comunicação e informação existentes na sociedade. As ações para aumentar as oportunidades de pessoas com deficiência no mercado de trabalho devem ser iniciadas pela disponibilização completa dos dados referentes às vagas de emprego para tornar a informação mais acessível. A padronização destas informaçóes pelas agências de emprego permitirá melhor conhecimento das pessoas 
com deficiência e possibilidade de escolhas. Somente com a compreensão dessas demandas é que serão eliminadas as barreiras iniciais para um real envolvimento de pessoas com deficiência nas atividades laborais e para uma efetiva participação social.

\section{Referências}

American Occupational Therapy Association - AOTA. (2014). Occupational therapy practice framework: domain and process. The American Journal of Occupational Therapy, 68(Supl. 1), S1-S48.

Bahia, M. S., \& Santos, E. M. (2009). Práticas empresariais para a inclusão profissional de pessoas com deficiência: um estudo de caso. In M. N. Carvalho-Freitas \& A. L. Marques (Eds.), Trabalho e pessoas com deficiência: pesquisas, práticas e instrumentos de diagnóstico (pp. 142-160). Curitiba: Juruá.

Baptista, A. K., \& Silva, F. C. M. (2011). Perfil demográfico e do emprego das pessoas com deficiência no município de Belo Horizonte, MG - Brasil. Revista Médica de Minas Gerais, 21(3), 288-297.

Betti, A. P. (2014). Perspectivas do emprego apoiado. Revista Deficiência Intelectual, 4(6), 12-16.

Borges, M. A. (2003). Uma contribuiçáo ao debate das políticas públicas de emprego: o Sistema Nacional de Emprego. Revista Abet, 3(1), 91-116.

Brasil. (1991a, 23 de maio). Decreto no 129, de 22 de maio de 1991. Promulga a Convenção no 159, da Organização Internacional do Trabalho - OIT, sobre Reabilitação Profissional e Emprego de Pessoas Deficientes. Diário Oficial [da] República Federativa do Brasil, Brasília. Recuperado em 10 de abril de 2019, de http://www.planalto.gov.br/ccivil_03/decreto/1990-1994/D0129.htm

Brasil. (1991b, 25 de julho). Lei no 8.213, de 24 de julho de 1991. Dispóe sobre os Planos de Benefícios da Previdência Social e dá outras providências. Diário Oficial [da] República Federativa do Brasil, Brasília. Recuperado em 14 de abril de 2019, de http://www.planalto.gov.br/ccivil_03/LEIS/L8213cons.htm

Brasil. (2006). Constituição da República Federativa do Brasil: texto constitucional promulgado em 5 de outubro de 1988, com as alteraçôes determinadas pelas Emendas Constitucionais de Revisão nos 1 a 6/94, pelas Emendas Constitucionais nos 1/92 a 91/2016 e pelo Decreto Legislativo no 186/2008. Brasília: Senado Federal, Coordenação de Ediçóes Técnicas. Recuperado em 14 de abril de 2017, de http://www2.senado.gov.br/bdsf/handle/id/522095

Brasil. (2011, 18 de novembro). Lei no 12.527 , de 18 de novembro de 2011 . Regula o acesso a informaçóes previsto no inciso XXXIII do art. $5^{\circ}$, no inciso II do $\$ 3^{\circ}$ do art. 37 e no $\$ 2^{\circ}$ do art. 216 da Constituição Federal; altera a Lei no 8.112, de 11 de dezembro de 1990; revoga a Lei no 11.111, de 5 de maio de 2005, e dispositivos da Lei no 8.159, de 8 de janeiro de 1991; e dá outras providências. Diário Oficial [da] República Federativa do Brasil, Brasília. Recuperado em 14 de abril de 2017, de http://www.planalto.gov.br/ccivil_03/_ato2011-2014/2011/lei/l12527.htm

Brasil. Secretaria Nacional de Promoção dos Direitos da Pessoa com Deficiência. (2012). Cartilha do censo: pessoas com deficiência. Brasília: SDH-PR/SNPD.

Brasil. (2015, 7 de julho). Lei no 13.146, de 6 de julho de 2015. Institui a Lei Brasileira de Inclusão da Pessoa com Deficiência (Estatuto da Pessoa com Deficiência). Diário Oficial [da] República Federativa do Brasil, Brasília. Recuperado em 13 de dezembro de 2018, de http://www.planalto.gov.br/ccivil_03/_Ato2015-2018/2015/Lei/L13146.htm

Brasil. (2017). Relação Anual de Informaçâo Social: RAIS 2017. Brasília: Ministério da Economia. Recuperado em 14 de janeiro de 2019, de http://www.rais.gov.br/sitio/tabelas.jsf

Carvalho, K. M. (2009). Os desafios da inclusão da pessoa com deficiência no ambiente de trabalho. In M. N. Carvalho-Freitas \& A. L. Marques (Eds.), Trabalho e pessoas com deficiência: pesquisas, práticas e instrumentos de diagnóstico (pp. 43-54). Curitiba: Juruá.

Coelho, C. M., Sampaio, R. F., \& Mancini, M. C. (2014). Trabalhadores com deficiência: vivências de prazer e sofrimento. Psicologia e Sociedade, 26(1), 214-223.

Cramm, J. M., Nieboer, A. P., Finkenflügel, H., \& Lorenzo, T. (2013). Comparison of barriers to employment among youth with and without disabilities in South Africa. Work, 46(1), 19-24. 
European Union of Supported Employment - EUSE. (2019). Supported employment explained: identifying features. Recuperado em 28 de janeiro de 2019, de http://www.euse.org/index.php/resources/whatis-se

García, V. G. (2014). Panorama da inclusão das pessoas com deficiência no mercado de trabalho no Brasil. Trabalho, Educação e Saúde, 12(1), 165-187.

Gil, A. C. (2002). Como elaborar projetos de pesquisa. São Paulo: Atlas.

Hammes, I. C., \& Nuernberg, A. H. (2014). A Inclusão de pessoas com deficiência no contexto do trabalho em florianópolis: relato de experiência no Sistema Nacional de Emprego. Psicologia: Ciência e Profissão, 35(3), 768-780.

Instituto Brasileiro de Geografia e Estatística - IBGE. (2010a). Censo demográfico do Brasil. Brasília. Recuperado em 25 de julho de 2019, de https://www.ibge.gov.br/estatisticas/sociais/trabalho/9662censo-demografico-2010.html?edicao $=9749 \& \mathrm{x}=$ resultados

Instituto Brasileiro de Geografia e Estatística - IBGE. (2010b). Censo demográfico do Brasil. Brasília. Recuperado em 25 de julho de 2019, de https://cidades.ibge.gov.br/brasil/mg/pesquisa/23/23612?detalhes=true\&localidade1=317010

Instituto Brasileiro de Geografia e Estatística - IBGE. (2015). Censo demográfico do Brasil. Brasília. Recuperado em 10 de abril de 2017, de http://censo2010.ibge.gov.br/

Lancman, S., \& Ghirardi, M. I. G. (2004). Introdução. In S. Lancman (Ed.), Saúde, trabalho e terapia ocupacional (pp. 9-13). Sáo Paulo: Roxa.

Leão, M. A. B. G., \& Silva, L. S. (2012). Vivências de trabalhadores com deficiência: uma análise à luz da Psicodinâmica do Trabalho. Revista Brasileira de Saúde Ocupacional, 37(125), 159-169.

Lorenzo, S. M., \& Silva, N. R. (2017). Contratação de pessoas com deficiência nas empresas na perspectiva dos profissionais de recursos humanos. Revista Brasileira de Educą̧ão Especial, 23(3), 345360.

Minas Gerais. Secretaria de estado da saúde de Minas Gerais. Superintendência Regional de Saúde. (2013). Diagnóstico situacional: saúde. Uberaba. Recuperado em 25 de julho de 2019, de https://www.mpmg.mp.br/lumis/portal/file/fileDownload.jsp?fileId=8A91CFAA42E2BC3E014372 0F01AA1DA7

Neves-Silva, P., Prais, F. G., \& Silveira, A. M. (2015). Inclusão da pessoa com deficiência no mercado de trabalho em Belo Horizonte, Brasil: cenário e perspectiva. Ciência \& Saúde Coletiva, 20(8), 25492558.

Organização das Naçóes Unidas - ONU. (2007). Optional protocol to the convention on the rights of persons with disabilities. United Nations. Recuperado em 25 de julho de 2017, de http://www.un.org/disabilities/documents/convention/convoptprot-e.pdf

Organização Internacional do Trabalho - OIT. (2001). Normas internacionais do trabalho sobre a reabilitação profissional e emprego de pessoas portadoras de deficiência. Brasília: CORDE. Recuperado em 17 de fevereiro de 2017, de http://www.oitbrasil.org.br/node/505

Organização Mundial da Saúde - OMS. (2003). CIF: Classificação Internacional de Funcionalidade, Incapacidade e Saúde. São Paulo: EdUSP.

Organização Mundial da Saúde - OMS. (2011). Relatório mundial sobre a deficiência. São Paulo: The World Bank.

Ramachandra, S. S., Murthy, G. V., Shamanna, B. R., Allagh, K. P., Pant, H. B., \& John, N. (2017). Factors influencing employment and employability for persons with disability: Insights from a City in South India. Indian Journal of Occupational and Environmental Medicine, 21(1), 36-41.

Sempertegui, M. M. (2015). Inclusión laboral de personas catalogadas como discapacitadas: algunas reflexiones para un debate necesario. Trabajo y Sociedad, (25), 405-442.

Simonelli, A. P., \& Camarotto, J. A. (2011). Análise de atividades para a inclusão de pessoas com deficiência no trabalho: uma proposta de modelo. Gestão \& Produção, 2(1), 13-26. 
Simonelli, A. P., Rodrigues, D. S., Navas, P. M. G., Soares, L. B. T., \& Camarotto, J. A. (2013). Projeto ATO: Ação, Trabalho e Oportunidade: inclusão de pessoas com deficiência no trabalho: relato de experiência. Cadernos de Terapia Ocupacional da UFSCar, 21(1), 119-130.

Souza, M. R., \& Kamimura, A. L. M. (2010). Pessoas com deficiência e mercado de trabalho. In $7{ }^{\circ}$ Seminário de Saúde do Trabalhador de Franca. Franca: Unesp. Recuperado em 20 de maio de 2017, de

http://www.proceedings.scielo.br/scielo.php?script=sci_arttext\&pid=MSC00000001120100001000 24\&lng=en\&nrm=abn

Toldrá, R. C., Marque, C. B., \& Brunello, M. I. B. (2010). Desafios para a inclusão no mercado de trabalho de pessoas com deficiência intelectual: experiências em construção. Revista de Terapia Ocupacional da Universidade de São Paulo, 21(2), 158-165.

Vagas.com (2017). Brasil: Vagas.com 2009-2017. Recuperado em 19 de abril de 2017, de https://www.vagas.com.br/

Verhoef, J., Bramsen, I., Miedema, H., Stam, H., \& Roebroeck, M. (2014). Development of work participation in young adults with cerebral palsy: a longitudinal study. Journal of Rehabilitation Medicine, 46(7), 648-655.

\section{Contribuiçáo dos Autores}

Fabiana Caetano Martins Silva e Dutra e Isadora

Teixeira Mendes Paz participaram do delineamento do estudo, coleta e discussão dos resultados da pesquisa, da redação e da revisão do artigo. Alessandra Cavalcanti participou da análise e discussão dos resultados e redação da versão inicial do artigo. Alberto Luiz Aramaki e Edinara Kososki participaram da discussão dos resultados e da revisão do artigo. Todos os autores aprovaram a versão final do texto.

\section{Autor para correspondência}

Fabiana Caetano Martins Silva e Dutra

e-mail: fabiana.dutra@uftm.edu.br 